УДК 330

\title{
ПРОБЛЕМА МАТЕМАТИЗАЦИИ ЭКОНОМИЧЕСКОЙ НАУКИ В ЭПОХУ МАРЖИНАЛИЗМА
}

\author{
Енина Анастасия Игоревна \\ Научный руководитель: Фаркова Наталья Анатольевна \\ канд.физ.-мат.наук, доцент \\ Дипломатическая академия МИД России
}

\begin{abstract}
Аннотация: В конце XIX века переход от качественного метода к количественному имел достоинства и недостатки в контексте объективности экономической теории. В работе рассмотрена эволюция маржинализма, проанализирована роль субъективизма в выдвинутых маржиналистами теориях, дана оценка использованию математических методов представителями различных школ маржинализма.

Ключевые слова: Эволюция экономической мысли, эпоха маржинализма, математические методы, полезность товара, маржиналистская революция.
\end{abstract}

\section{THE PROBLEM OF ECONOMICS MATHEMATIZATION IN THE AGE OF MARGINALISM}

\section{Enina Anastasia Igorevna Farkova Natalia Anatolievna}

\begin{abstract}
At the end of the 19th century, shifting from the qualitative method to the quantitative one had several advantages and disadvantages in the context of the objectivity of economic theory. The article reviews the marginalism evolution, analyzes the role of subjectivism in the theories put forward by marginalists, and assesses the use of mathematical methods by marginalists of different scientific schools.
\end{abstract}

Key words: Evolution of economic thought, the age of marginalism, mathematical methods, utility, the Marginal Revolution. 
Эволюция экономической мысли сопровождалась поиском новых методологических подходов к решению текущих и перспективных задач, возникающих по мере экономического развития. Долгое время экономика оставалась наукой качественной: до XIX века ученые-экономисты описывали, интерпретировали, объясняли тенденции и закономерности социальноэкономических явлений, преимущественно не прибегая к операции измерения.

Смена классической политэкономии на теорию маржинализма была обусловлена кризисом экономической теории, когда в последней трети XIX века длительная депрессия мировой экономики выразила фазу спада большого экономического цикла. Кризис теории есть кризис метода, что ведет к переоценке и ценностей и восприятия новых идей, которые ранее игнорировались $[1$, с. 96]. Такими стали идеи маржиналистского анализа ценообразования. Сторонники данной теории поднимали вопрос об эффективном взаимодействии экономических явлений. Среди предшественников нового направления отметим Германа Г. Госсена, Антуана О. Курно и Иоганна Г. фон Тюнена. Используемый системный подход привел их к мысли о необходимом равновесии экономической системы на разных уровнях.

Отличительной чертой нового теоретического направления являлось исследование предельных величин. Экономические процессы моделировались маржиналистами математически, в виде дифференциальных уравнений - и именно Курно в 1838 году в книге «Исследования математических принципов в теории богатства», опираясь на применение математического аппарата, ввел и определил понятия экономического равновесия, функции спроса, эластичности спроса и др. [2, с. 9]. Широкое использование математического аппарата ознаменовало математизацию - метод формализации научного знания, подразумевающий проведение процедур измерения, сравнения, счета [3, c. 164].

Новым в маржиналистской теории стало соединение понятий полезности и редкости товара. Предельная полезность определяется следующим образом:

$$
M U=\frac{d T U}{d Q}
$$

где TU (total utility) - общая полезность, Q (quantity) - объём потребляемой продукции.

Снижение предельной полезности единицы товара в краткосрочном периоде связано с постепенным насыщением им. Другими словами, каждая 
последующая единица товара будет приносить все меньшее удовлетворение потребностей (Таблица 1). Однако открытие Закона убывающей предельной полезности приписывается не маржиналистам, а их предшественнику немецкому ученому-экономисту Г. Госсену.

Таблица 1

Потребление товара X

\begin{tabular}{|c|c|c|}
\hline Количество товара, Q & Общая полезность, TU & $\begin{array}{c}\text { Предельная полезность, } \\
\text { MU }\end{array}$ \\
\hline 0 & 0 & - \\
\hline 1 & 10 & 10 \\
\hline 2 & 16 & 3 \\
\hline 3 & 19 & 1 \\
\hline 4 & 20 & 0 \\
\hline 5 & 20 & 6 \\
\hline
\end{tabular}

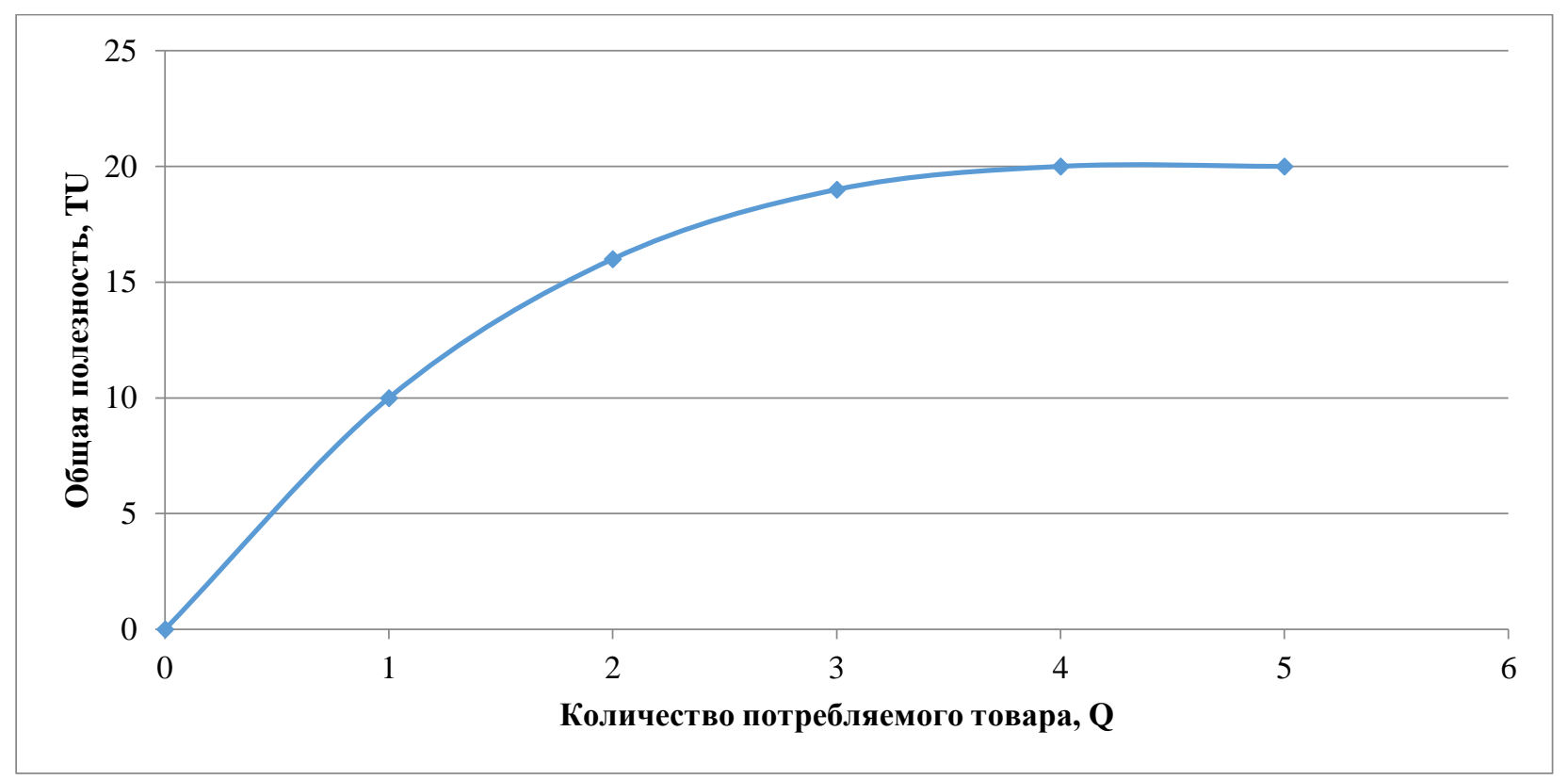

Рис. 1. Зависимость общей полезности от потребления товара 


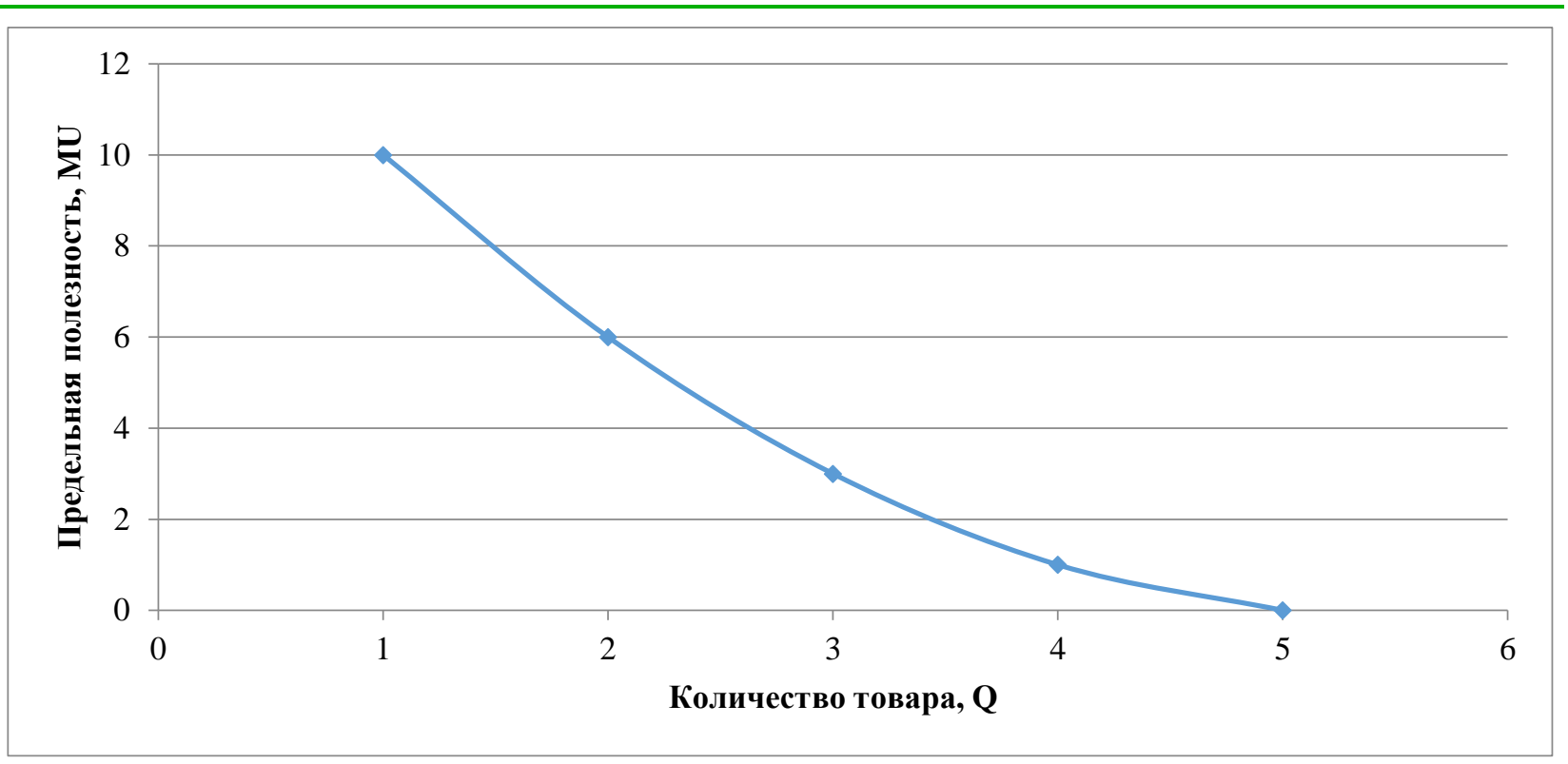

Рис. 2. Зависимость предельной полезности от потребления товара

Графическая интерпретация Закона убывающей предельной полезности наглядно демонстрирует, что линия общей полезности является выпуклой ввиду замедления темпов роста TU (рис. 1), а кривая предельной полезности снижается в результате уменьшения предельной полезности по мере потребления дополнительных единиц данного товара (рис. 2).

Маржиналисты разных периодов использовали преимущественно одинаковые математические методы, тем не менее, внедрение математического аппарата было неспособно полностью решить проблему субъективности теории полезности.

Период формирования маржиналистской теории условно делят на два этапа [4, с. 92]. Ранний маржинализм относится к 70-80-м гг. ХІХ века. «Маржиналисткую революцию» начали независимо от друга три экономистатеоретика: К. Менгер в Австрии, У. Джевонс в Англии и Л. Вальрас в Швейцарии. Представители данного этапа заменили теорию стоимости, определяя последнюю предельной полезностью. Таким образом, первичной сферой экономики стало потребление, а не производство.

Наиболее влиятельная школа раннего маржинализма была основана на национальных научных традициях Австрии. Понятие «австрийская школа» характеризует подход к пониманию полезности как субъективный. К. Менгер и его последователи отказывались от использования математических методов. Индивидуальная оценка полезности благ - один из примеров субъективизма как методологического подхода представителей австрийской школы. Кроме 
того, существенным элементом их методологии является субъективное восприятие информации. Несмотря на то, что все участники рыночных отношений обладают рациональным поведением, они допускают «предпринимательские ошибки», если на рынке остаются необнаруженные возможности получить прибыль.

Труды У. Джевонса не обладали популярностью до конца XIX века ввиду математической формы самовыражения. Его современники-экономисты не желали применять математические методы в решении проблем социального характера. Однако максимальное удовлетворение потребностей при минимуме усилий представлялось ему сугубо экономической задачей, не связанной с политическими, моральными и другими факторами. Не поддерживая идею К. Менгера о субъективной оценке полезности товара, английский экономист установил функциональную зависимость предельной полезности от товарных цен, трактуемых издержками производства.

Известный представитель лозаннской школы маржинализма Л. Вальрас первым разработал теорию общественного равновесия. В своей основной работе «Элементы чистой политической экономики» (1874-1877) он занимался математическим моделированием экономики. Заметно ее упростив, Л. Вальрас исследовал «чистую» экономику, игнорируя ее социальные составляющие.

Второй этап «маржиналистской революции» обозначается с середины 80-х до конца 90-х гг. ХІХ века. Смена предмета исследования был обусловлен отказом от выделения первичной сферы экономики: теперь маржиналисты рассматривали экономику в целом. Предельные величины стали использоваться ими не только применительно к проблемам спроса, но и к проблемам предложения. Теоретики данного этапа получили также название «неоклассики» - англичанин А. Маршалл, американец Д.Б. Кларк, итальянец В. Парето. Они заменили причинно-следственные связи в экономике функциональными и отказались от понятия стоимости. Теперь цена в равной степени зависела от спроса и предложения; ее понятие стало результатом синтеза двух теорий стоимости - определяемой производственными затратами и определяемой полезностью.

Заслугой английского экономиста А. Маршалла является отказ от понятия политической экономии в пользу понятия экономики, что характеризовало условность математических моделей маржиналистов. В своих работах он подчеркивал наличие определенных допущений, которые не 
всегда соответствовали реальности [5, с. 187]. Предпочтение отдавалось графическим методам математического анализа, что сопровождалось также лишними погрешностями в силу особенностей метода.

Метод анализа, используемого Дж.Б. Кларком, основывался на положениях Дж.С. Милля о статике и динамике. Равновесие экономических параметров представлялось статичным, их изменение приводило к динамичному состоянию экономической системы. Д.Б. Кларк отмечал, что статичное состояние в экономике недостижимо, так как естественные системы динамичны. Однако, как и другие маржиналисты той эпохи, он ограничился исследованием лишь экономической статики.

Будучи последователем лозаннской школы маржинализма, У. Парето также занимался исследованием «чистой» экономики. Рассмотрев проблему общего экономического равновесия для трех типов экономик - свободной конкуренции, монополизированной, центрально-управляемой, - он сделал свою работу актуальной еще на несколько десятилетий вперед. Кроме того, У. Парето отказался от подходов количественной характеристики полезности и ее субъективной оценки, тем самым совершив переход от кардиналистской трактовки полезности к ординалистской.

Представители «маржинальной революции» стремились максимизировать полезность благ, поэтому Менгер, Джевонс, Вальрас и Маршалл искали абсолютную величину полезности для возможного соизмерения. Количественную оценку потребительской полезности товара в абсолютном выражении У. Джевонс проводил с использованием введённой им единицы измерения «утиль». Субъективизм - слабая сторона кардиналистской теории - заключается в оценке степени потребности в товаре. Попытка найти абсолютную величину полезности привела к созданию кардиналистской теории, согласно которой максимизация полезности описывается вторым Законом Госсена:

$$
\frac{M U_{a}}{P_{a}}=\frac{M U_{b}}{P_{b}}=\cdots=\frac{M U_{n}}{P_{n}},
$$

здесь $M U_{a}$ - предельная полезность товара A, $P_{a}$ - цена товара А.

При условии полного расходования дохода предельные полезности товаров в расчете на одну затраченную у. е. должны быть равны.

Альтернативным подходом в оценке потребительской полезности товара являлся ординалистский. По мнению Парето, невозможно измерить абсолютную величину полезности, поэтому он предложил измерить ее 
порядковую величину. В развитие нового подхода огромный вклад был внесен английским экономистом Дж.Хиксом. Выбор покупателя исключал субъективную оценку полезности и выражал акт предпочтения одного товара другим. Построение так называемой карты безразличия не требовало измерения абсолютного уровня полезности.

В ординалистском анализе предпочтений одних комбинаций товаров другим в качестве инструмента используются кривые безразличия, каждая точка которых характеризуют комбинации количества этих товаров. Выпуклая к началу координат форма прямых с отрицательным наклоном говорит о нежелаемом постепенном отказе от некоторого количества одного товара в пользу его несубститута. Точка пересечения бюджетной линии и кривой безразличия отражает оптимальную комбинацию товаров для потребителя при заданных условиях. Чтобы остаться на данном уровне удовлетворения потребностей при отказе от некоторого количества одного товара в пользу дополнительных единиц другого, измеряется предельный уровень замещения:

$$
M R S_{x}^{y}=\frac{M U_{x}}{M U_{y}}
$$

где $X$ - товар, ради которого отказываются от товара $Y$.

В попытке отказа от количественной оценки величины полезности ординалисты ввели понятие предельной нормы замещения, которое сопряжено со вторым Законом Госсена, используемым кардиналистами. Раскроем суть понятия $M R S_{x}^{y}$ из (3):

$$
M R S_{x}^{y}=\frac{M U_{x}}{M U_{y}}=\frac{\frac{T U_{x}}{Q_{x}}}{\frac{T U_{y}}{Q_{y}}}=\frac{T U_{x} Q_{y}}{T U_{y} Q_{x}} .
$$

Раскроем суть второго Закона Госсена (2):

$$
\frac{M U_{x}}{P_{x}}=\frac{\frac{T U_{x}}{Q_{x}}}{P_{x}}=\frac{\frac{T U_{y}}{Q_{y}}}{P_{y}}=\frac{M U_{y}}{P_{y}}, \frac{T U_{x}}{Q_{x} P_{x}}=\frac{T U_{x}}{Q_{x} P_{x}}, \frac{P_{x}}{P_{y}}=\frac{T U_{x} Q_{y}}{T U_{y} Q_{x}},
$$

что выражает норму предельного замещения. Таким образом, условия равновесия, установленные ординалистами, совпадают с кардиналистскими условиями равновесия.

Развитие эпохи маржинализма сопровождалось активным использованием математических методов. Предметом исследования являлась 
равновесная система с ограниченным количеством ресурсов. Главной задачей исследования стал поиск оптимального использования ресурсов для максимизации прибыли субъекта на микроуровне или общественного благосостояния на макроуровне. В работах маржиналистов разных периодов экономика представлялась рынком совершеннной конкуренции [6, с. 274], на котором субъекты свободны и рациональны. Равновесие отождествлялось с экономической статикой. По мере своей эволюции маржинализм избавлялся от субъективности используемых понятий, заимствовал некоторые элементы классической политэкономии и продолжил развитие своих идей уже в рамках неоклассической школы.

В эпоху маржинализма экономические теории строились по канонам математики. С одной стороны, подход к экономике как к разновидности социальной математики исключал из работ исследователей субъективную составляющую. Экономические законы требуют объективности, поэтому внедрение математического аппарата в экономику было необходимо и остается актуальным. Математические модели успешно использовали для решения поставленных задач, графический метод анализа открывал возможности визуализации экономических процессов. С другой стороны, ученые-экономисты пренебрегали адекватностью выдвигаемых концепций и не заботились о принадлежности их к экономике как к социальной науке. Принятые допущения превращали экономические теории в идеализированные модели, которые априори невозможно осуществить в реальности.

\section{Список литературы}

1. Шлычков В.В., Нестулаева Д.Р. Кризис экономической теории как отправная точка ее дальнейшего развития // ВЭПС. 2013. №4 - С. 95-98.

2. Барлыбаев А.А., Юнусова Г.М. Математические методы в экономической науке: эволюция и перспективы // Экономический анализ: теория и практика. 2009. №23 - С. 9-14.

3. Фаркова Н.А., Худякова О.Ю. Математический инструментарий в экономике. NEW CHALLENGES IN NEW SCIENCE : сборник статей Международной научно-практической конференции (25 ноября 2020 г.). Петрозаводск: МЦНП «Новая наука», 2020. - 346 с. : ил. DOI 10.46916/30112020-2-978-5-00174-048-3 - C. 159-167. 
4. Покидченко М. Г., Чаплыгина И.Г. История экономических учений: Учебное пособие. М.: ИНФРА-М, 2008. - 271 с.

5. Иваницкий, В. Л. История экономических учений : учебник для академического бакалавриата / М: Издательство Юрайт, 2019. — 282 с.

6. Ядгаров Я.С. История экономических учений: Учебник для вузов. 3е издание. - М.: ИНФРА-М, 2000. - 320 с. 